\title{
POLISHING TECHNIQUES EFFECT ON MICROHYBRID, NANOHYBRID AND NANOFILLED COMPOSITES COLOR AND SURFACE ROUGHNESS STABILITY
}

\author{
EFEITO DE TÉCNICAS DE POLIMENTO NA ESTABILIDADE DA COR E \\ RUGOSIDADE SUPERFICIAL DE RESINAS COMPOSTAS MICROHIBRIDAS, \\ NANOHIBRIDAS E NANOPARTICULADAS
}

\begin{abstract}
Vera Lucia SCHMITT ${ }^{1}$; Flavia Pardo Salata NAHSAN ${ }^{2}$; Fabiana Scarparo NAUFEL ${ }^{3}$; Savil Costa VAEZ ${ }^{4}$; Guilherme Schmitt de ANDRADE ${ }^{5}$; Wagner BASEGGIO ${ }^{6}$; Mário Alexandre Coelho SINHORETI ${ }^{7}$; Regina Maria PUPPIN-RONTANI ${ }^{8}$

1. Adjunct Professor, Departament of Restorative Dentistry, Parana West State University, Cascavel, PR, Brazil. veraschmitt@uol.com.br; 2. Adjunct Professor, Department of Dentistry, Aracaju Federal University; 3. Associated Professor, Departament of Restorative Dentistry, Parana West State University, Cascavel, PR, Brazil; 4. Msc in Dentistry, Aracaju Federal University; 5. Private Surgeon Dentist, Parana West State University, Cascavel, PR, Brazil;; 6. Adjunct Professor, Paranaense University, Cascavel, PR; 6. Assistant Professor, Dental Materials Division, Department of Restorative Dentistry, Piracicaba Dental School, UNICAMP, Campinas, SP, Brazil; 7. Assistant Professor, Department of Pediatric Dentistry, Piracicaba Dental School, UNICAMP, Piracicaba, SP, Brazil.
\end{abstract}

\begin{abstract}
Resin roughness and staining is a common problem in dentistry. Objective: the aim of this study was to verify the influence of single and multiple-steps polishing techniques on color stability and surface roughness of differents composite resins. Groups were $(n=10)$ : FS+CS. Filtek Supreme XT + clear strip; FS+PG. Filtek Supreme $\mathrm{XT}+\mathrm{PoGo}$; FS+SF. Filtek Supreme XT+Sof-Lex; AM+CS. Amelogen+clear strip; AM+PG. Amelogen+PoGo; AM+SF. Amelogen+Sof-Lex; TEC+CL .TetricEvoCeram + clear strip; TEC+PG .Tetric EvoCeram+ PoGo; TEC+SF .Tetric EvoCeram+Sof-Lex; CED+CS .Ceram X Duo+clear strip; CED+PG. Ceram X Duo+PoGo; CED+SF. Ceram X Duo+SofLex. The initial color and roughness were determined before and after the polishing procedures. All specimens were stored for 7 days in coffee solution and the color assessment was performed. Two specimens from each group were evaluated by scanning electron microscopy. Roughness and color data were submitted to ANOVA and Tukey tests $(\mathrm{p}<0.05)$. All tested materials presented color alterations after coffee solution storage; the highest $\Delta \mathrm{E}$ values were observed for clear strips and all composite resins, as following: $\mathrm{G} 4 \quad(9 \mathrm{~h})>\mathrm{G} 7(5.8 \mathrm{f})=\mathrm{G} 10(5.7 \mathrm{ef})>\mathrm{G} 1(3.7 \mathrm{c})$, followed by the $\mathrm{G} 6(5.9 \mathrm{f})>\mathrm{G} 9(3.1 \mathrm{bc})=\mathrm{G} 12(2.1 \mathrm{ab})>\mathrm{G} 3(1.7 \mathrm{a})$. G3, after 7 days, presented the lowest values for $\Delta \mathrm{E}(1.704)$. The lowest roughness values were observed when the clear strips were used regardless material type. The Sof-Lex system provided the lowest surface roughness values for all tested composite resins. Among composite resins the highest roughness values were found for Amelogen (G5-0.49 and G6-0.35), regardless polishing technique. All tested materials presented changes in color after immersion in coffee solution. The roughness surface and the staining of composite resins are material and polishing technique dependents.
\end{abstract}

KEYWORDS: Dental polishing. Dental materials. Nanotechnology.

\section{INTRODUCTION}

New restorative materials with large application on daily basis dentistry have been launched as a response for the technological improvement of composite resins and for the increased aesthetics request by patients. However, the failure and success of an aesthetic restoration is dependent on chosen material, as well as color stability and material physical-mechanical properties (YAP, YAP, TEOCK, 2004; BARAKAH, TAHER, 2014).

Composite resin's composition and structure and filler's characteristics present direct impact on surface smoothness and staining susceptibility (VENTURINI et al., 2006, JEFFERIES, 2007). Finishing and polishing procedures may also influence the surface quality of composite resins (NAHSAN et al, 2014).

Lately, several modifications on the fabrication of lightcured composite resins were accomplished and the major development has been done to the fillers' system, aiming to decrease the mean size of particles and decrease alterations in geometry, and also to incorporate greater quantities of inorganic components into the resin matrix (MITRA, WU, HOLMES , 2003, TERRY, 2004). A different mineral and distinct filler shapes have been employed to reduce polymerization shrinkage, to specially achieve better color stability, adequate wear resistance and clinically acceptable surface smoothness, resulting in better aesthetic results (MITRA, WU, HOLMES, 2003; YAP, YAP, TEOCK, 2004 ; TERRY, 2004).The type, size and 
quantity of filler particles influence extrinsic material staining, affecting the surface roughness. The resin matrix and filler particles do not wear at the same rate due to different physical properties. Particle degradation might occur after polishing procedures, leading consequently to irregularities on restoration surface, affecting surface smoothness and favoring surface stain accumulation. These factors are related to initial phases of material staining.

Color stability is an important parameter for modern restorative resin-based materials. Resin matrices have influences on color stability. Hydrophilic resin matrices tend to absorb more water and are easily stained in comparison to hydrophobic matrices, once water constitutes a vehicle for dye penetration (BUCHALLA et al., 2002). The type of chosen particle (glass, fumed silica, and others) similarly influences composite resin staining (BUCHALLA et al., 2002). The finishing and polishing procedures, besides the effects of material composition and conversion degrees, might influence the surface quality of composite resins, directly in relation to staining and roughness (YAP et al., 1997, VENTURINI et al., 2006, JEFFERIES, 2007, ERGÜCÜ, TURKÜN, 2007, ALANDIA-ROMAN et al., 2013).

Finishing refers to restoration contouring or reduction in order to reproduce ideal anatomic characteristics. Polishing by its turn, is related to reduction of roughness, microgaps and surface irregularities created by finishing instruments (JEFFERIES, 2007, GÖNÜLOL, YILMAZ, 2012).

Adequate finishing and polishing procedures of composite resins potentiate aesthetics results and restoration longevity. Rough surfaces predispose restorations to increased biofilm retention, leading to development of recurrent caries lesion, discoloration and staining (YAP et al., 1997), besides interfering with final shine and aesthetics (YAP et al., 1997).

Finishing and polishing procedures require the sequential employment instruments, usually with gradual decrease of abrasive particles, aiming to achieve a shiny and smooth surface (JONES, BILLINGTON, PEARSON, 2004). The highly flexible discs impregnated with aluminum oxide are the most employed materials for this purpose (YAP, YAP, TEOCK, 2004). Recently however, synthetic silicon abrasive rubber points were launched into market aiming to produce an adequate smooth and shiny resin surface, with reduction of steps and required clinical time for finishing and polishing (KORKMAZ et al., 2008.). Manufactures name this system as "single-step polishing procedure", once a single instrument is employed. This polishing concept fulfills dentists' requirements for obtaining clinically acceptable and smooth surfaces using a single instrument in a shorter period of time (YAP, YAP, TEOCK, 2004, ERGÜCÜ, PEARSON, 2004, TURKÜN, 2007, JONES, BILLINGTON, ERGÜCÜ, TURKÜN, ALADAG, 2008).

However, the literature is not unanimous regarding the effectiveness of different finishing and polishing systems for composite resins. While some studies demonstrate the prior use of multi-blade instruments to discs or abrasive rubber points is a determinant step to achieve surface smoothness (TURSSI, FERRACANE, SERRA, 2005), others report the effectiveness of single-step polishing systems (SERRA, 2005, ERGÜCÜ, TURKÜN, 2007, ERGÜCÜ, TURKÜN, ALADAG, 2008, TURSSI, FERRACANE,).

Several methods for color assessment were recently developed, including spectrophotometry and colorimetry, which made possible the study of numerous parameters related to color stability in composite resins.

For this study, a spectrophotometer, which measures precise sections of the visible light spectrum and bases on the specimen body reflection by specific wavelengths, was chosen. This wavelength measurement method reports values of specimen reflection in $\Delta \mathrm{E}^{*}$ units. $\Delta \mathrm{E}^{*}$ values can be used to represent color changes presented by restorative materials after a certain treatment or period of time.

According to the variety of composite resins and polishing systems available for dental marketing, it is important to assess them especially to determine which polishing system provides better surface smoothness effect for determined composite resin (. Moreover, it is important to determine the relationship between the surface roughness characteristics of composite resins and color maintenance over time.

Facing this issue, the objective of the present study was to evaluate the effect of singlestep or multiple-step polishing techniques on (YAP, YAP, TEOCK, 2004) color stability and (VENTURINI et al., 2006) surface roughness of four composite resins.

In the present study, the tested hypotheses are that different dental composite resins according to type, size and compaction of fillers when submitted to different polishing techniques present different patterns of staining and surface roughness. 


\section{MATERIAL AND METHODS}

For this study, a nanofilled composite resin: Filtek Supreme XT (3M ESPE, St Paul, MN, USA), two nanohybrid composite resins: TetricEvoCeram (IvoclarVivadent, Schaan, Liechtenstein) and Ceram $\mathrm{X}$ Duo (Dentsply, Konstanz, Germany), and a microhybrid composite resin: Amelogen (UltradentInc., South Jordan, UT, USA) were used.

One hundred and twenty specimens were fabricated using a metallic matrix with dimension of $7 \mathrm{~mm}$ in diameter and $2 \mathrm{~mm}$ in width. The specimens were divided into 12 groups $(\mathrm{N}=10)$ according to the association of composite resin type and polishing system, as described on groups (cr + treatments): 1Filtek Supreme + Mylar Strip; 2 - Filtek Supreme + PoGo; 3 - Filtek Supreme + Sof-Lex; 4 Amelogen + Mylar Strip; 5 - Amelogen + PoGo; 6 - Amelogen + Sof-Lex; 7 TetricEvoCeram + Mylar Strip; 8 -TetricEvoCeram + PoGo; 9 - TetricEvoCeram + Sof-Lex; 10 - Ceram X Duo + Mylar Strip; 11 - Ceram X Duo + PoGo and 12 - Ceram X Duo + Sof-Lex.

Composite resin was inserted into the matrix and covered by a clear strip and pressed with $2 \mathrm{~mm}$ thick glass slides. Specimens were lightcured for 40 seconds using a halogen light - Curing Light 2500 (3M/ESPE, Saint Paul - MN, USA), with power density of $500 \mathrm{~mW} / \mathrm{cm}^{2}$. Its power density was checked with a radiometer before each irradiation. The specimens were stored at $37^{\circ} \mathrm{C}$ and $100 \%$ absolute humidity for 24 hours prior the initial color measurement.

The initial color of all specimens was determined using a VITA Easyshade spectrophotometer (Vident, Brea, CA, USA), following the CIELAB scale (Commission Internationale de $1^{\prime}$ Eclairage), with $\mathrm{L}^{*}, \mathrm{a}^{*}$ and $\mathrm{b}^{*}$ coordinates and $\Delta \mathrm{E}^{*}$ determined by the equation $\triangle \mathrm{E}=\left[(\Delta \mathrm{L})^{2}+(\Delta \mathrm{a})^{2}+(\Delta \mathrm{b})^{2}\right]^{1 / 2} . \mathrm{L}^{*}$ refers to shade from 0 to 100 (from black to white), $a^{*}$ refers to colorfulness $(-80$ to +80 , negative green value and positive red) and $b^{*}(-80$ to +80 , negative blue value and positive yellow).

The referred spectrophotometer measures precise sections of visible light at the $400 \mathrm{~nm}$ to 700 $\mathrm{nm}$ range, based on the reflection of specimenspecific wavelength and translates values reported in $\Delta \mathrm{E}^{*}$, which are not influenced by environment colorfulness. $\Delta \mathrm{E}^{*}$ values can be used to represent restorative material color changes underwent after a determined treatment of period of time (ERGÜCÜ, TURKÜN, 2007). According to Lee et al., (ATTAR, 2007), $\Delta \mathrm{E}^{*}<1$ relates to color alterations not detected by human eye; $\Delta \mathrm{E}^{*}<3.3$ - clinically acceptable color alterations; and $\Delta \mathrm{E}^{*}>3.3$ - clinically not acceptable color alterations, resulting in need of restoration replacement due to aesthetics.

The measurement was performed three times per specimen. After each specimen reading, the instrument was calibrated for the next specimen assessment.

Specimens were submitted to the different polishing procedures in low speed following the manufacturer's instructions. One single operator performed the specimens polishing to reduce the technique variability of this phase.

To evaluate polishing effect on specimen surface smoothness, the specimen's surface roughness was assessed at the end of polishing procedures using a surface roughness measuring instrument Surf-Corder (Kosaka Lab. SE 1700). The mean surface roughness ( $\mathrm{Ra}$ ), obtained by three consecutive measurements in different surface locations, was the used parameter.

For the assessment of staining resistance of composite resins, the specimens were immersed in coffee solution (Nescafe, Nestlé, Switzerland, Batch 91591210B) for seven days. Coffee solution was the choice for being an extremely consumed product in Brazil and worldwide. Fifteen grams of coffee were added to $500 \mathrm{~mL}$ boiling water and filtered $10 \mathrm{~min}$ prior to placement in the storage recipients with the specimens (ERGÜCÜ, TURKÜN, ALADAG, 2008). The solution was changed every 24 hours.

Before color assessment, specimens were washed in distilled water for one minute and dried with absorbent paper. The specimen's final color was assessed following the same protocol described for the initial color measurement.

Data were submitted to 2-way ANOVA and Tukey test for individual comparisons among the different groups, both with level of significance set at $5 \%,(\mathrm{P}<0.05)$.

Two specimens from each group were evaluated through scanning electronic microscopy (SEM - JEOL JLM 5600 LV) for the qualitative surface analysis and possible correlations between composite resin and polishing system with surface smoothness. They were gold metalized to assure visualization at $50 \mathrm{X}$ magnification and to observe fillers' size and geometry under 1000X magnification.

\section{RESULTS}

The statistical analysis (2-way ANOVA) determined the existence of significant interaction among the factors composite resins and polishing 
techniques $(\mathrm{P}<0.05)$, for the studied variables, surface roughness and staining after immersion in coffee solution (Delta E). Multiple comparisons were carried out with Tukey test, which revealed differences among groups.
The mean values and standard deviation for composite resins and polishing systems are presented on figures 1 and 2 and respectively represent the mean values for Delta $\mathrm{E}$ and surface roughness (Ra expressed in $\mu \mathrm{m}$ ).

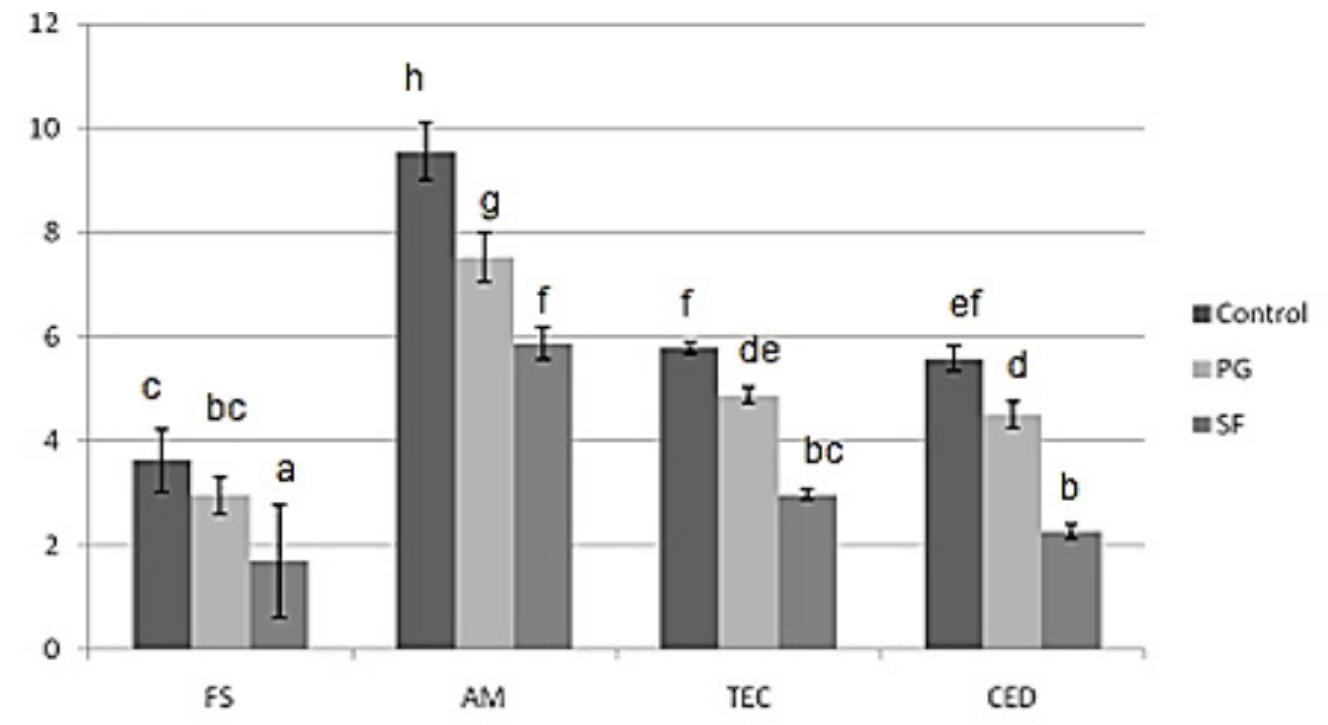

Figure 1. Delta E mean values of the resins Filtek (FS), Amelogen (AM), TetricEvo Ceram (TEC) and Ceram $X$ Duo (CED). Control- Clear Strip, PG- Pogo and SL- Sof Lex. Columns identified by the same small letters do not significantly differ according to Tukey test $(\mathrm{P}>0.05)$.

FS composite resin and CED submitted to the Sof-Lex polishing system and after one week immersed in coffee solution, presented the lowest values for Delta E. All tested materials presented changes in color after immersion in coffee solution; and the highest values for Delta E were observed in the control group for each material type followed by the Pogo and Sof-Lex system.

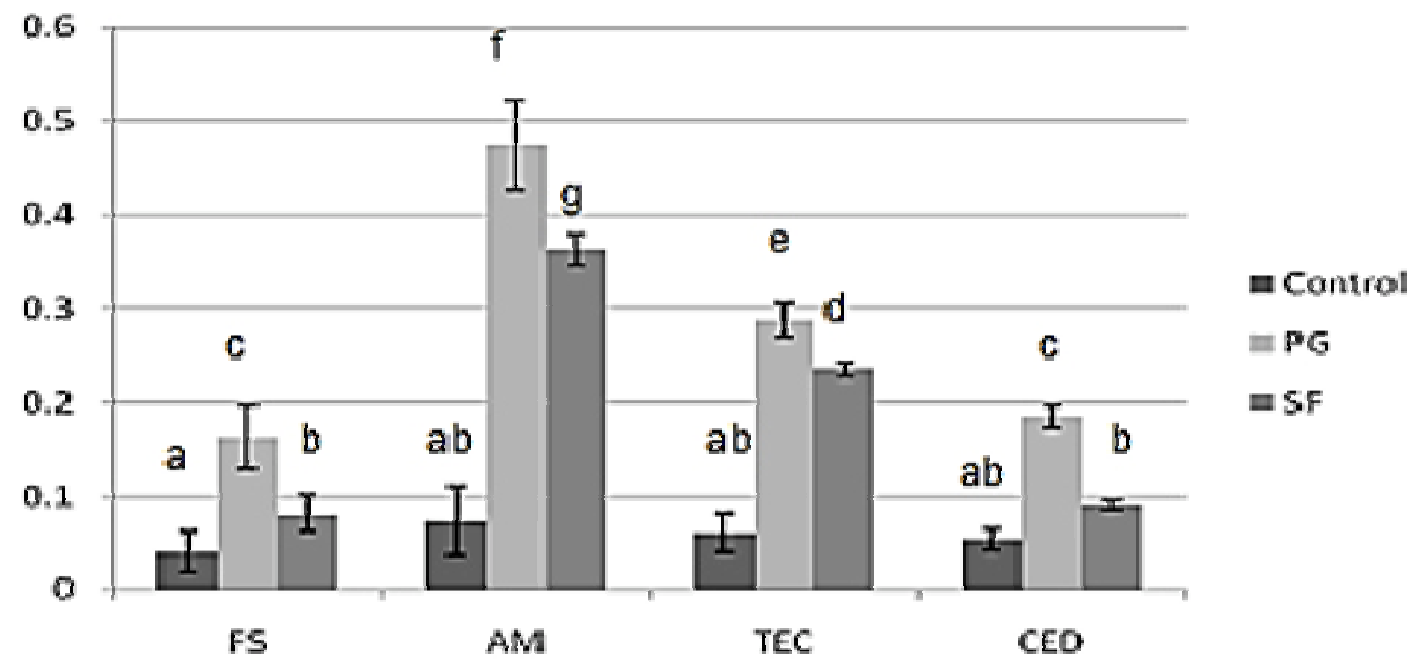

Figure 2. Final Roughness Mean surface roughness values $(\mu \mathrm{m})$ and standard deviation according to employed material type and polishing technique. Control- Clear Strip, PG- Pogo and SL- Sof Lex. Columns identified the same small letters do not significantly differ according to Tukey test $(\mathrm{P}>0.05)$. The critical value for $\mathrm{Ra}$ is 0.2 .

For the roughness values, the lowest values were observed when the clear strip was used regardless material type. Between the polishing techniques employed, the Sof-Lex system presented the lowest surface roughness values for all tested composite resins.

Statistical analysis revealed that regardless polishing technique, Amelogem composite resin 
presented the highest $\triangle \mathrm{E}^{*}$ values and roughness after treatment.

Multiple comparisons using Tukey test determined that Filtek Supreme (FS) and Ceram X Duo (CED) specimens presented the lowest roughness variation when polished with the Sof-Lex (SL) system, those being statistically different from TetricEvoCeram (TEC) and Amelogem (AM). (Figure 3)

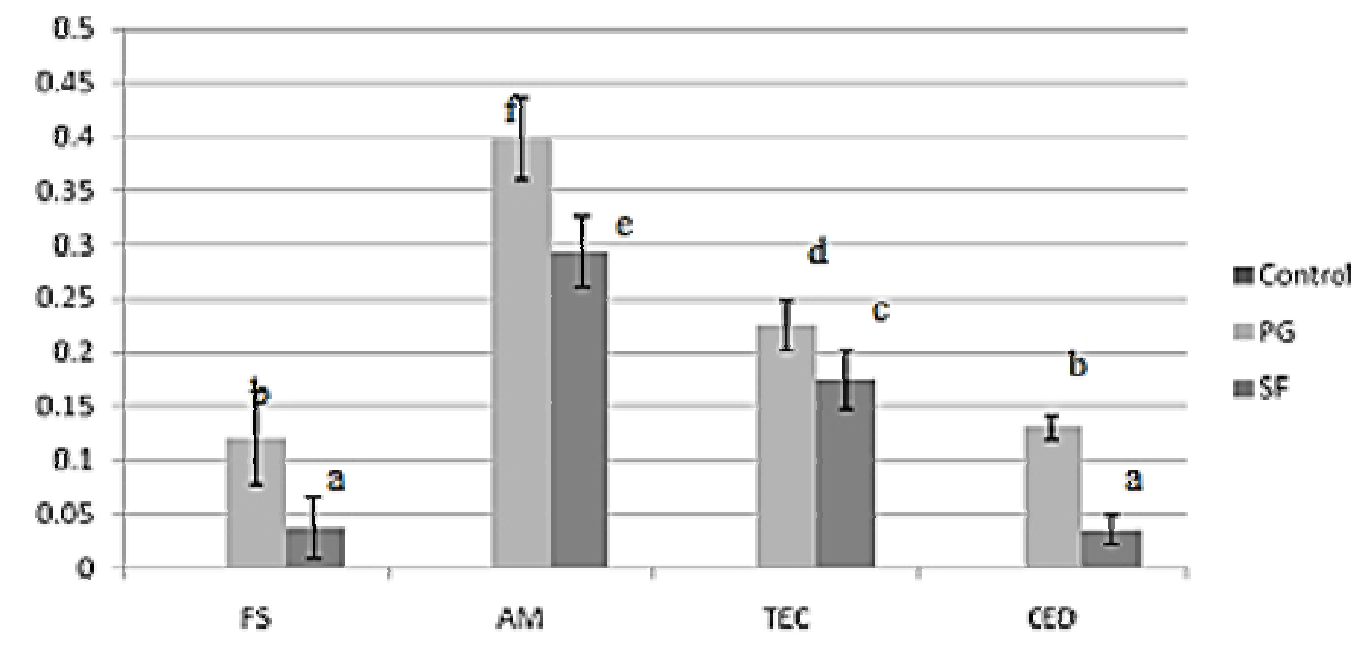

Figure 3. Roughness -Variation $(\mathrm{Ra})$ Surface rougness variation according to employed material type and polishing technique. Control- Clear Strip, PG- Pogo and SL- Sof Lex. Columns identified by the same letters do not significantly differ according to Tukey test $(\mathrm{P}>0.05)$.

\section{DISCUSSION}

Finishing and polishing procedures have been associated to lower bacterial plaque retention, lower marginal discoloration and consequent increased longevity for aesthetic restorations.

The tested hypotheses of this study were proved once significant interactions between different composite resins and polishing techniques were observed.

Lower surface roughness values were observed for the association of Filtek Supreme composite resin and Sof-Lex multiple-step polishing system. This observation could probably be attributed to material composition and influenced by filler type, particles size and quantity, particles distribution within organic matrix (Figure 4), which interfere with the mechanical properties and polishing degree of composite resins (YAP, YAP, TEOCK, 2004). For the nanocomposites, the nanometer-sized particles combination reduces interstitial space among fillers, leading to improvements on surface physical characteristics (ATTAR, 2007, UCTASLI, 2007).

According to polishing procedures, lower surface roughness values were observed for the nanofilled composite resins with the multiple-step polishing procedure (Figure 3). A possible explanation for this fact relies on composition and employment directions of the aluminum oxide discs.
As they are employed in decreasing grit order, they promote even surface wear and polishing, regardless the composite resin type. This effect is potentiated for the nanofilled composite resins, once wear occurs by individual breakage of nanometer-sized particles, preserving the nanoclusters as reported by Turssi et al., (TURSSI, FERRACANE, SERRA, 2005), and resulting in surfaces with defects smaller than the light wavelength (MITRA, WU, HOLMES, 2003).

The fabrication of nanofilled composite resins occurs by associating small particles in a more favorable thermodynamic pattern leading to formation of aggregates and clusters (MITRA, WU, HOLMES, 2003). This might explain the low surface roughness observed for the Filtek Supreme specimens when submitted to the Sof-Lex polishing system. This nanocluster preservation is possible due to strong chemical interaction between nanocluster and resin matrix.

According to the present results, smoothest surfaces were obtained when the clear strip was used, regardless the type of tested composite resins, due to the emergence of resin organic matrix (YAP, LYE, SAU, 1997, YAP, YAP, TEOCK, 2004). This matrix emergence, besides promoting better surface texture, might lead to faster degradation of restoration surface due to the characteristics of the formed polymer. This surface is also limited by the anatomy complexity and restorative procedures, 
being the functional occlusal adjustment necessary in almost every restoration (COSTA et al., 2007).

Inorganic particles of composite resins are more difficultly abraded than the resin matrix, and they might be lost during finishing and polishing procedures. This will result in a filler positive relief on the surface (TURSSI, FERRACANE, SERRA, 2005); thus the larger the particles the larger the relief, reflecting on the roughness (Figure 4).

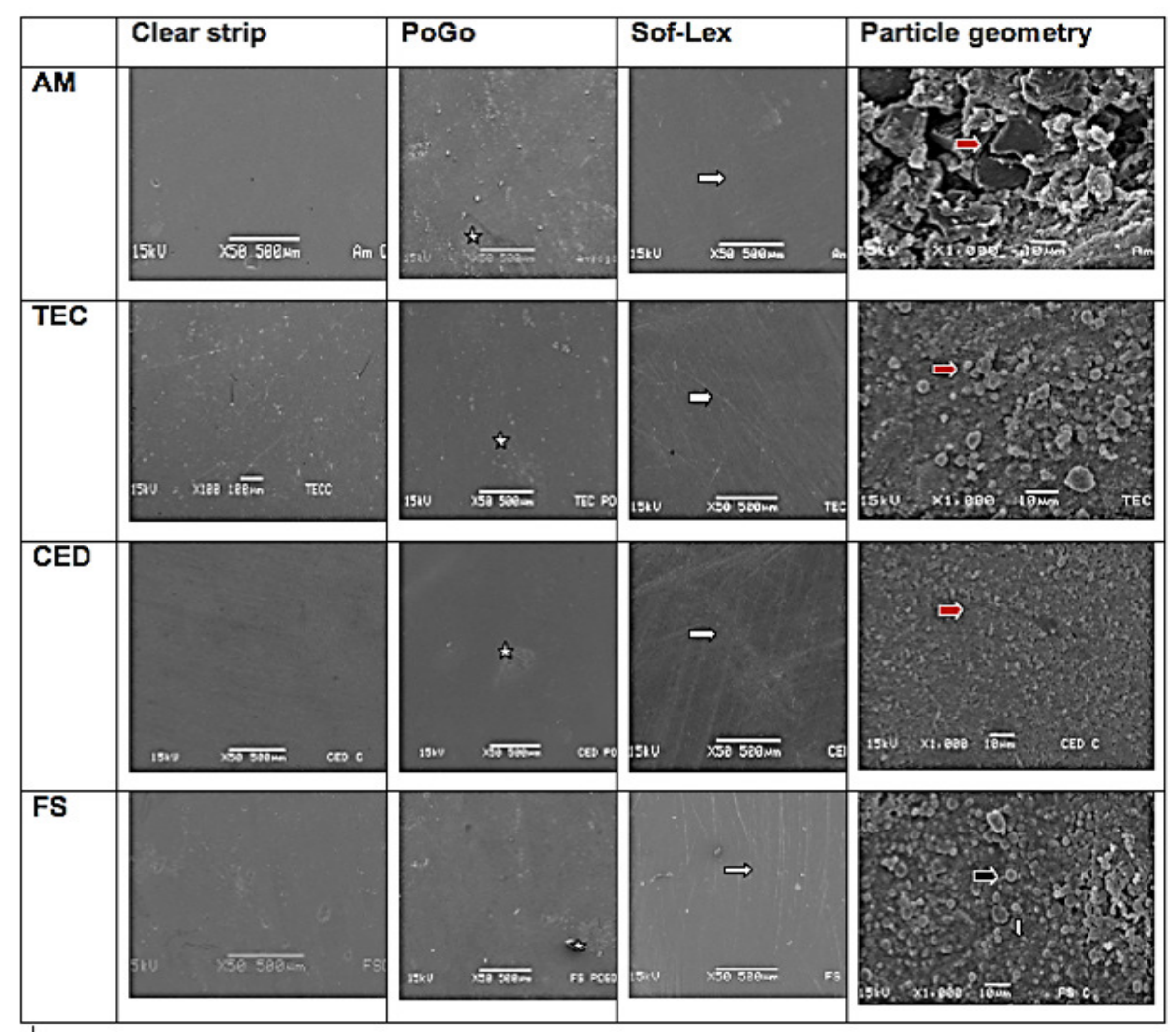

Figure 4. Microphotographs of Filtek supreme (FS); TetricEvoCeram (TEC); Ceram X Duo (CED) and Amelogem (AM) composite resins are disposed in the rows. Columns are represented by control (clear strip); after polishing with Sof-Lex discs; after polishing with PoGo system (original SEM 50X) and composite resin particles geometry on the last column (original SEM 1000X). Observe the surface smoothness promoted by the clear strip (column 1); the irregular surface promoted by PoGo system (stars); the more uniform surface promoted by Sof-Lex system (column 3) (50X magnification), besides some noticed scratches (with arrows). The last column presents a greater magnification (1000X) of the composite.

A relationship between filler size and surface roughness can be observed, as the microhybrid composite resin Amelogem, composed by inorganic particles with bigger size and uneven borders, presented greater surface smothiness results with the two tested polishing systems, being this observation in agreement with reported results (SENAWONGSE; PONGPRUEKSA, 2007). When the particles size is reduced, and nanomer-sized are incorporated to matrix, an improvement in surface smoothness is expected, as observed in the present study results for the composite resins Ceram X Duo and TetricEvoCeram. The relationship between filler size and surface roughness can be also observed when comparing the nanohybridcomposites among them. As an example, Ceram X Duo presents smaller sized particles in comparison to TetricEvoCeram and thus, presented lower surface roughness regardless the employed polishing system.

The results showed that Sof-Lex ${ }^{\mathrm{TM}}$ discs promote smoother surfaces than PoGo polishing system. The effects of finishing and polishing systems show surface roughness was polishing system and composite resin dependent. Researches show that Sof-Lex ${ }^{\mathrm{TM}}$ aluminum oxide flexible discs are the best instruments for promoting low composite resin surface roughness (LU, ROEDER, POWERS, 2003). Uctasli, (UCTASLI, 2007), demonstrated aluminum oxide discs are able to 
propitiate smooth surfaces, and this fact is related to the ability of those discs to evenly reduce filler and matrix, favoring their employment for composites presenting smaller sized fillers (ROEDER, POWERS, 2003, VENTURINI et al., 2006, LU, JUNG, EICHELBERGER, KLIMEK, 2007).

The abrasive particles of a composite resin finishing system should be harder than the material particles in order to be efficient. On the contrary, the polishing agent would only remove soft matrix and leave highly leveled fillers on the surface. Aluminum oxide is harder than silicon oxide and usually harder than fillers employed for composite resin formulations (SARAC, 2006). According to Jefferies (JEFFERIES, 2007), fine aluminum oxide particles are hard enough to polishing ceramic and composite resin.

Contrasting with the present results, Turkun LS, Turkun M. in 2004 e Yap.et. al. in 2004 observed that one-step polishing systems are as efficient as multiple-step systems for composite resin polishing.

Color determination in dentistry has been done for many years through color guides to visually identify colors (JOHNSTON, KAO, 1989); however, previous studies observed this visual assessment as being inconsistent and lacking in reliability. Instrumental methods using electronic optics and informatics, have been developed to eliminate uncontrolled variables during the color determination process, leading to a more adequate technique of electronic color selection for daily basis use (ERGÜCÜ, TURKÜN, 2007), once they are able to detect subtle color changes. According to Yap et al., (YAP et al., 1999), in cases where $\Delta \mathrm{E}^{*}$ value is greater than 3 , the computerized analysis is better than naked eye.

$\triangle \mathrm{E}^{*}$ values in the control groups for all tested composite resins showed more intense staining and the color $\triangle \mathrm{E}^{*}$ crescent degree was 3.62 for Filtek supreme; 5.57 for Ceram X Due; 5.78 for TetricEvoCeram and 9.54 for Amelogem. According to Ergücü et al., (ERGÜCÜ, TURKÜN, 2007), all Mylar-finished specimens showed the most intense staining due to the outermost resin layer. Therefore, removal of this resin layer by finishing and polishing procedures would produce a harder, more stain resistant and, hence, more esthetically stable surface. Moreover, surfaces present higher quantities of organic matrix as a result of pushing the material with clear strips.

A decrease in $\Delta \mathrm{E}^{*}$ values were observed in relation to polishing procedures for all tested composite resins, indicating the removal of the most superficial non cured composite layer by finishing and polishing procedures results in a surface more staining resistant and consequently a more aesthetically acceptable surface. These results are in agreement with Ergücü et al., (ERGÜCÜ, TURKÜN, ALADAG, 2008).

Differences in chemical structures of composite resins, such as types of employed oligomers or monomers, concentration/type of activators, initiators and inhibitors, oxidation of carbon-carbon double bonds, size/type of fillers and bonding system might influence color stability (ERGÜCÜ, TURKÜN, ALADAG, 2008).

All tested composite resins presented detectable color changes after immersion in coffee solution. The effect of the staining solution was material dependent according to the observed results Ergücü et al., (ERGÜCÜ, TURKÜN, ALADAG, 2008). An association between filler size and color change could be detected in the present study, as the Filtek Supreme nanocomposite presented the lowest staining values, followed by the nanohybrid and microhybridcomposite resins. This observation is in agreement with Kawaguchi et al., (KAWAGUCHI, FUKUSHIMA, MIYAZAKI, 1994), who detected that composite resins with large-sized inorganic fillers are more prone to water sorption and color alterations.

Moreover, color might be related to polymer and filler/matrix phase, or even to polymer filler interface. The filler/matrix interface performs an important water uptake role for composite resins (BUCHALLA et al., 2002), being color stability directly related to hydrophilic characteristics of composite resin matrix, which will contribute to greater staining. Thus, as higher the composite resin water uptake, the higher the volume of formed polymer and consequently there will be greater spaces for water molecules to diffuse within the polymeric structure (GULLER et al., 2009). A mixture of UDMA and bis-EMA provides a higher hydrophobicity to composite resins and consequently higher stability, confirming the present results obtained for Filtek Supreme. On the other hand, TetricEvoCeram presents Bis-GMA and TEGDMA in its composition, and those monomers are more hydrophilic, leading to more water absorption, fact confirmed by the present $\triangle E^{*}$ values. Furthermore, the present tested nanohybrid composite TetricEvoCeram presented higher $\triangle \mathrm{E}^{*}$ values than Ceram $X$ Duo. This fact may be attributed to the presence of ytterbium trifluoride on TetricEvoCeram's composition. This component provides a certain fluoride release and according to Buchalla et al., (BUCHALLA et al., 2002), this 
component may be soluble and influence on the optical characteristics of the material.

\section{CONCLUSION}

Based on the present results, it can be concluded that both the surface roughness and staining $\left(\triangle E^{*}\right)$ are influenced by the composite resin type and by the polishing technique. Multiplestep polishing technique is more favorable in achieving surface smoothness and staining resistance regardless resin type. Nanofilled composite resin presented greater staining resistance. Surface smoothness and composite staining are material and polishing technique dependent.

RESUMO: Rugosidade e pigmentação de resinas são problemas comuns em odontologia. Objetivo: Avaliar influência das técnicas de um e múltiplos-passos de polimento na estabilidade de cor e rugosidade de resinas. Os grupos $(\mathrm{n}=10)$ : G1.Filtek Supremo XT+Tira poliéster; G2.Filtek SupremeXT+PoGo; G3.Filtek Supreme XT+ Sof-Lex; G4.Amelogen+Tira poliéster; G5.Amelogen + PoGo; G6.Amelogen + Sof-Lex; G7.Tetric EvoCeram +Tira poliéster; G8.Tetric EvoCeram+PoGo; G9.Tetric EvoCeram+Sof-Lex; G10.CeramXDuo+Tira poliéster; G11.Ceram X Duo+PoGo; G12.Ceram X Duo+Sof-Lex. A Cor inicial e rugosidade foram determinadas antes e apóso polimento. Após, foram armazenadas durante 7 dias em solução de café e nova avaliação da cor foi realizada. Dois espécimes de cada grupo foram avaliados pela microscopia eletrônica de varredura. Dados de rugosidade e cor foram submetidos à ANOVA e teste Tukey ( $\mathrm{p}<0,05)$. Todas as resinas testadas apresentaram alterações de cor após armazenamento em solução de café; foram observados os maiores valores de AE em tiras de poliésterpara as resinas,a seguir: $\mathrm{G} 4(9 \mathrm{~h})>\mathrm{G} 7(5,8 \mathrm{f})=\mathrm{G} 10(5,7 \mathrm{ef})>\mathrm{G} 1$ $(3,7 \mathrm{c})$, seguindo-se a G6 $(5,9 \mathrm{f})>9(3,1 \mathrm{bc})=\mathrm{G} 12(2,1 \mathrm{ab})>\mathrm{G} 3(1,7 \mathrm{a})$. G3, após 7 dias, apresentaram os menores valores para AE (1,704). Menores valores de rugosidade foram observados para as tiras de poliéster, independentemente do material. Menores valores de rugosidade foram encontrados no sistema Sof-Lex. Entre as resinas valores maiores de rugosidade foram encontrados para Amelogen (G5-0,49 e G6-0,35), para as duas técnicas. Todos os materiais testados apresentaram alterações na cor após imersão em solução de café. A rugosidade e pigmentação das resinas compostas são dependentes da técnica e material.

PALAVRAS-CHAVE: Polimento dentário. Materiais dentários. Nanotecnologia.

\section{REFERENCES}

ALANDIA-ROMAN C. C., CRUVINEL D. R., SOUSA A. B., PIRES-DE-SOUZA F. C., PANZERI H. Effect of cigarette smoke on color stability and surface roughness of dental composites. J Dent. v. 41, n. 3, p. 73-9, 2013. http://dx.doi.org/10.1016/j.jdent.2012.12.004

ATTAR, N. The Effect of Finishing and Polishing Procedures on the Surface Roughness of Composite Resin Materials. J Contemp Dent Pract. v. 8, n. 1, p. 27-35, 2007.

BARAKAH, H. M., TAHER, N. M. Effect of polishing systems on stain susceptibility and surface roughness of nanocomposite resin material. J Prosthet Dent. v. 112, n. 3 p. 625-31, 2014.

doi:10.1016/j.prosdent.2013.12.007

BUCHALLA, W.; ATTIN. T.; HILGERS, R. D.; HELLWIG, E. The effect of water storage and light exposure on the color and translucency of a hybrid and a microfilled composite. J Prosthet Dent. v. 87, p. 264-70, 2002. doi:10.1016/j.prosdent.2013.12.007

COSTA, J.; FERRACANE, J.; PARAVINA, R. D.; MAZUR, R. F.; ROEDER, L. The Effect of Different Polishing Systems on Surface Roughness and Gloss of Various Resin Composites. J EsthetRestor Dent. v. 19, p. 214-226, 2007. http://dx.doi.org/10.1111/j.1708-8240.2007.00104.x

ERGÜCÜ, Z.; TURKÜN, L. S. Surface roughness of novel resin composites polished with one-step systems. Oper Dent. v. 32, n. 2, p. 185-92, 2007. http://dx.doi.org/10.2341/06-56

ERGÜCÜ, Z.; TURKÜN, L. S.; ALADAG, A. Color stability of nanocomposites polished with one-step systems. Oper Dent. v. 33, n. 4, p. 413-20, 2008. http://dx.doi.org/10.2341/07-107 
GÖNÜLOL, N.; YILMAZ, F. The effects of finishing and polishing techniques on surface roughness and color stability of nanocomposites. J Dent. v. 40, n. 2, p. 64-70, 2012. http://dx.doi.org/10.1016/j.jdent.2012.07.005

GULLER, AU.; GULLER, E.; YUCEL, A. C, ERTAS, E .Effects of polishing procedures on color stability of composite resins. J. Appl Oral Sci.; v. 17, n. 2, p. 108-1, 2009.

JEFFERIES, S. R. Abrasive Finishing and Polishing in Restorative Dentistry: A State-of-the-Art Review. Dent Clin N Am. v. 51, p. 379-397, 2007. http://dx.doi.org/10.1016/j.cden.2006.12.002

JOHNSTON, W. M.; KAO; E. C. Assessment of appearance match by visual observation and clinical colourimetry. J Dent Res. v. 68, p. 819-822, 1989. http://dx.doi.org/10.1177/00220345890680051301

JONES, C. S.; BILLINGTON, R. W.; PEARSON, G. J. The in vivo perception of roughness of restorations. British Dental Journal. v. 196, n. 1, p. 42-45, 2004. http://dx.doi.org/10.1038/sj.bdj.4810881

JUNG, M.; EICHELBERGER, K.; KLIMEK, J. Surface geometry of four nanofiller and one hybrid composite after One-step and multiple-step Polishing. Operative Dentistry. v. 32, n. 4, p. 347-355, 2007.

http://dx.doi.org/10.2341/06-101

KAWAGUCHI, M.; FUKUSHIMA, T.; MIYAZAKI, K. The Relationship Between Cure Depth and Transmission Coefficient of Visible-light-activated Resin Composites. J Dent Res. v. 73, n. 2, p. 516-521, 1994.

KORKMAZ, Y.; OZEL, E.; ATTAR, N.; AKSOY, G. The influence of one-step polishing systems on the surface roughness and microhardness of nanocomposites. Oper Dent. v. 33, n. 1, p. 44-50, 2008. http://dx.doi.org/10.2341/07-28

LU, H.; ROEDER, L. B.; POWERS, J. M. Effect of polishing systems on the surface roughness of microhybrid composites. Journal of Esthetic Restorative Dentistry, v. 15, n. 5, p. 297-303, 2003.

http://dx.doi.org/10.1111/j.1708-8240.2003.tb00300.x

MITRA, S. B.; WU, D.; HOLMES, B. N. An application of nanotechnology in advanced dental materials. JADA, v. 134, n. 10, p. 1382-90, 2003. doi:10.14219/jada.archive.2003.0054

NAHSAN, F. P. S., SILVA, L. M.; BASEGGIO, W., FRANCISCONI, P. A. S, FRANCO, E. B., MONDELLI, R. F. L. Effect of sealants in the composite surface roughness after tooth brushing. Bioscience Journal, v. 30, n. 6, p. 1959-1966, 2014.

SARAC, D., SARAC, S., KULUNK, S., URAL, C., KULUNK, T. The effect of polishing techniques on the surface roughness and color change of composite resins. J Prosthet Dent. v. 96, p. 33-40, 2006.

http://dx.doi.org/10.1016/j.prosdent.2006.04.012

SENAWONGSE, P.; PONGPRUEKSA, P. Surface Roughness of Nanofill and Nanohybrid Resin Composites after Polishing and Brushing. J Esthet Restor Dent. v. 19, p. 265-275, 2007. http://dx.doi.org/10.1111/j.17088240.2007.00116.x

TERRY, D. A. Direct applications of a nanocomposite resin system. Part 1.The evolution of contemporary composite materials. Pract Proced Aesht Dent. v. 16, n. 6, p. 417-22, 2004.

TURSSI, C. P.; FERRACANE, J. L.; SERRA, M. C. Abrasive wear of resin composites as related to finishing and polishing procedures. Dental materials. v. 21, n. 7, p. 641-48, 2005.

http://dx.doi.org/10.1016/j.dental.2004.10.011 
UCTASLI, M. B.; ARISU, H. D.; OMURLU, H.; ELIGUZELOGLU, E.; OZCAN, S.; ERGUN, G. The Effect of Different Finishing and Polishing Systems on the Surface Roughness of Different Composite Restorative Materials. J Contemp Dent Pract. v. 8, n. 2, p. 89-96, 2007.

VENTURINI, D.; CENCI, M. S.; DEMARCO, F. F.; CAMACHO, G. B.; POWERS, J. M. Effect of polishing techniques and time on surface roughness, hardness and microleakage of resin composite restorations. Oper Dent. v. 31, n. 1, p. 11-7, 2006. http://dx.doi.org/10.2341/04-155

YAP, A. U.; LYE, K. W.; SAU, C. W. Surface characteristics of tooth-colored restoratives polished utilizing different polishing systems. Operative Dentistry. v. 22, n. 6, p. 260-265, 1997.

YAP; A. U.; YAP; S. H.; TEOCK; N. G. J. J. Finishing/polishing of composite and compomer restoratives: effectiveness of one-step systems. Oper Dent. v. 29, n. 3, p. 275-79, 2004.

YAP; A. U.; SIM; C. P.; LOH, W. L.; TEO, J. H. Human-eye versus computerized colour matching.Oper Dent. v. 24, p. 358-363, 1999. 